\title{
DIFERENCIAÇÕES ENTRE AS ENFERMIDADES HEMORRÁGICAS DOS SUÍNOS
}

\author{
ALMEIDA, Henrique Meiroz de Souza ${ }^{1}$ \\ GATTO, Igor Renan Honorato ${ }^{1}$ \\ MARINI, Rodrigo de Lemos ${ }^{2}$ \\ OLIVEIRA, Maria Emilia Franco ${ }^{3}$ \\ SAMARA, Samir Issa ${ }^{3}$ \\ OLIVEIRA, Luís Guilherme de
}

ISSUE DOI: $10.3738 / 1982.2278 .980$

\begin{abstract}
RESUMO: As doenças de caráter hemorrágico em geral se originam de agentes infecciosos. A ocorrência dessas enfermidades causa impactos diretos à sanidade do rebanho e ao status sanitário da produção nacional, o que pode levar ao levantamento de barreiras comerciais. Dentre as enfermidades infecciosas que apresentam hemorragias como um dos principais sinais clínicos, algumas têm destaque mundial por serem doenças de notificação compulsória segundo a Organização Mundial de Saúde Animal (OIE), sendo a Peste Suína Clássica (PSC) e Peste Suína Africana (PSA), estas em particular disseminam rapidamente causando problemas sanitários, ambientais, sociais e grandes prejuízos para o setor. Outras enfermidades não enquadradas como de notificação obrigatória, como a Erisipela, Pasteurelose e Samonelose, também representam grandes problemas aos plantéis nacionais causando prejuízos de menor escala a produção, mesmo assim o controle dessas enfermidades se torna imprescindível. O principal problema na identificação é a estreita relação entre algumas enfermidades e a semelhança entre sinais clínicos, dificultando a diferenciação dessas doenças com quadros hemorrágicos. Este trabalho teve como objetivo realizar uma revisão de literatura sobre como identificar e realizar o diagnóstico diferencial entre as enfermidades hemorrágicas dos suínos.
\end{abstract}

Palavras Chave: Suínos. Enfermidades. Hemorragias. PSC, PSA

\section{DIFFERENTIATION OF THE HAEMORRHAGIC DISEASES OF SWINE}

SUMMARY: The haemorrhagic diseases of swine are usually caused by infectious agents. The occurrence of these diseases causes direct effects on the swine herd health and on the sanitary status of the country's production, which can lead to the raise of sanitary barriers. Among the infectious diseases with haemorrhagic clinical signs, some have more importance for being diseases of compulsory notification to the World Organization of Animal Health (OIE), like the Classical Swine Fever (CSF) and the African Swine Fever (ASF), both of them spread quickly in the herd causing problems of sanitary, environmental, social natures and money losses. Other diseases such as Erysipelas, Salmonellosis and Pasteurellosis, despite of not being of compulsory notification, also represent a big problem to the national swine herd health causing animal and money losses, that's why it is extremely important knowing how to control these diseases. The main problem on diagnosing and differentiating the mentioned diseases is the similarity of the haemorrhagic clinical signs between them and the strict relation that the etiological agents can show. This literature review has the purpose of bringing information of how to diagnose and differentiate these swine's haemorrhagic diseases.

Keywords: Swine. Disease. Haemorrhagic. CSF, ASF

\footnotetext{
${ }^{1}$ Pós-Graduação em Medicina Veterinária (Medicina Veterinária Preventiva), Faculdade de Ciências Agrárias e Veterinárias/ Universidade Estadual Paulista (FCAV/UNESP)

${ }^{2}$ Graduação em Medicina Veterinária, Faculdade de Ciências Agrárias e Veterinárias/ Universidade Estadual

Paulista (FCAV/UNESP)

${ }^{3}$ Departamento de Medicina Veterinária Preventiva e Reprodução Animal, Faculdade de Ciências Agrárias e

Veterinárias/ Universidade Estadual Paulista (FCAV/UNESP)

${ }^{4}$ Coordenadoria de Defesa Agropecuária / Secretaria de Agricultura e Abastecimento (SAA-SP)
} 


\section{INTRODUÇÃO}

As doenças hemorrágicas de suínos podem apresentam sinais clínicos semelhantes dificultando a diferenciação entre elas. Obter um diagnóstico exato é necessário para se decidir quais as medidas de tratamento e saneamentos serão mais eficientes para a contenção e eliminação da enfermidade do rebanho acometido, evitando maiores prejuízos.

Dentre as enfermidade com sinais clínicos hemorrágicos, possuem maior importância, a Peste Suína Clássica (PSC), a Peste Suína Africana (PSA), Erisipela, Pasteurelose e Salmonelose. No caso das duas primeiras a importância está no fato de serem doenças de notificação obrigatória para a Organização Mundial da Saúde Animal (OIE), enquanto que nas três últimas a importância está na frequência na qual elas ocorrem nos rebanhos suínos. Essas enfermidades podem ser confundidas com facilidade devido a uma série de sinais clínicos em comum que apresentam. Sendo assim, os sinais clínicos, as lesões causadas, os meios de diferenciação e o diagnóstico das enfermidades citadas são de grande utilidade para os médicos veterinários, que trabalham na suinocultura, e por isso será alvo de análise deste artigo de revisão.

\section{Peste Suína Clássica}

A Peste Suína Clássica (PSC), é uma enfermidade infecciosa, altamente contagiosa causada por um vírus do gênero Pestivirus, albergado por suínos domésticos e selvagens (OIE, 2009). Acomete suínos de todas as idades, apresentando em sua forma aguda, um quadro de hemorragias generalizadas com alta morbidade e mortalidade (SOBESTIANSKY et al., 1999a). Trata-se de uma enfermidade de grande importância sócio-econômica tais os prejuízos que determina (MAYR; GUERREIRO, 1972).

O suíno é o único hospedeiro da enfermidade e a principal fonte de infecção, sendo que o contato direto entre animais sadios e acometidos é o principal meio de transmissão viral (OIRSCHOT, 1999). Os suínos infectados começam a eliminar o vírus para o ambiente antes mesmo do aparecimento dos sinais clínicos, principalmente por meio das fezes, urina, secreções nasais e lacrimais (OIRSCHOT, 1999; BLOOD; RADOSITITS, 1989a). Fêmeas prenhes, quando infectadas podem não apresentar sinais clínicos e parirem leitões infectados com o vírus, estes últimos podem resistir à infecção clínica durante longos períodos, facilitando na disseminação do agente etiológico (BLOOD; RADOSTITS, 1989a).

A doença é caracterizada por alta morbidade e mortalidade, os animais acometido apresentam febre, inapetência, apatia, constipação, diarreia, eritema cutâneo generalizado, paresia dos movimentos, hemorragias, cianose nas extremidades e ainda pode ocorrer um quadro de vasculite no sistema nervoso central que leva incoordenação e até mesmo convulsões 
(EDWARD, 2011; KRZYZANIAK et al., 2002) . A degeneração do epitélio vascular, em conjunto com intensa trombocitopenia, levam ao aparecimento de manchas hemorrágicas na pele, linfonodos e diversas outras vísceras (PIEROZAN et al., 2008).

A presença de infartos multifocais na borda do baço são frequentemente encontrados à necropsia dos animais acometidos da PSC, sendo quase considerada como sinal patognomônico de PSC (OIE, 2009). Entre outras lesões, também podem ser citados botões ulcerativos na junção ileocecal devido à infecção conjunta com Salmonella spp, atrofia de timo, hemorragias petequiais e sufusões em pericárdio, epicárdio, endocárdio, toráx, rins, bexiga, epiglote e abdômen (EDWARDS, 2011; SOBESTIANSKY, et al., 1999a; MAYR ; GUERREIRO, 1972).

O diagnóstico da PSC é realizado através do isolamento viral de amostras de órgãos como tonsilas, baço, rins e porção mais distal do íleo, outros exames também podem ser utilizados, como hemograma, no qual se observa leucopenia e trombocitopenia acentuadas; teste de ELISA e exame histopatológico do cérebro onde se nota acúmulo de células inflamatórias ao redor dos vasos devido à vasculite (SOBESTIANSKY et al., 1999a). O teste de imunofluorescência direta (IFD) utilizado em cortes de tonsila de suínos de matadouros, apresentou boa sensibilidade para se diagnosticar a doença (BERSANO et al., 2001).

\section{Peste Suína Africana}

A Peste Suína Africana (PSA) é uma arbovirose causada pelo Vírus da Peste Suína Africana (VPSA), microrganismo antigenicamente diferente do vírus da PSC, apesar de ambas as enfermidades serem semelhantes clinicamente (SOBESTIANSKY, 1999b; BLOOD; RADOSTITS, 1989b). Esse vírus utiliza carrapatos do gênero Ornithodorus $s p$ para realizar seu ciclo no meio selvagem, podendo sobreviver longos períodos nesses vetores na ausência de fontes de infecção (SANCHEZ-VIZCAINO, 1992; BLOOD; RADOSTITS, 1989b).

Os suínos selvagens são resistentes à infecção agindo epidemiologicamente como reservatórios e fonte de infecção para os animais domésticos, que uma vez acometidos espalham a doença rapidamente eliminando o vírus pelas secreções oronasais, urina e fezes (BLOOD; RADOSTITS, 1989b). A transmissão transnacional pode ocorrer através de resíduos de portos e aeroportos contendo carne suína crua ou cozida contaminada com o vírus (SANCHEZVIZCAINO, 1992).

De modo geral, as enfermidades, apresentam um quadro clínico e patológico muito semelhante, apesar da PSA apresentar lesões hemorrágicas de maior intensidade, maiores índices de mortalidade e morbidade (SOBESTIANSKY et al., 1999b). Ao exame de necropsia de animais acometidos em um surto de PSA no município do Rio de Janeiro em 1978, foi 
encontrada, pneumonia intersticial difusa, lesões no endotélio dos vasos, necrose em áreas do fígado e baço bastante congesto (TOKARNIA, et al., 2004).

Moura (2009) afirma que algumas diferenças entre as formas clínicas da PSA e a PSC devem ser destacadas, tais como o fato de animais com PSA não apresentarem encefalite, diarreia, inapetência e perda de peso. Blood e Radostits (1989b) afirmam que a PSA possui evolução mais curta do que a PSC podendo ser diferenciadas dessa forma, mas mesmo assim recomendam o uso de provas sorológicas e virológicas. Os testes de diagnóstico mais comumente utilizados são ELISA, IFD e testes de hemadsorção do vírus (SOBESTIANSKY et al.,1999b; BLOOD; RADOSTITS, 1989b).

\section{Erisipela}

Outra doença hemorrágica comum é a erisipela ou ruiva. Essa enfermidade é causada pela bactéria do gênero Erysipelothrix spp, sendo a espécie mais comum em suínos a Erysipelothrix rhusiopatiae, mais patogênica e responsável pela maioria dos casos da doença (OLIVEIRA, 2009). A enfermidade acomete suínos de todas as idades, sendo que leitões em fase de maternidade apresentam certa resistência à infecção devido aos anticorpos colostrais (IMADA $e t$ al., 2003). A principal porta de entrada para o agente, é a via oral, através da ingestão de água e alimentos contaminados, ou da lambedura de feridas na pele de animais infectados (OLIVEIRA, 2009).

A forma aguda da doença apresenta sinais clínicos como febre, anorexia, relutância em andar, além das altas taxas de mortalidade (OLSEN, 2004). Nessa fase podem ser notados diversos tipos de lesões, desde regiões eritematosas na pele, áreas cianóticas (principalmente nas orelhas, focinho e abdômen), até lesões na forma de losango distribuídas por todo o corpo, principalmente no dorso e flanco (CAMEROM, 2011). O aparecimento de lesões em forma de losangos é um sinal patognomônico dessa doença, outras lesões hemorrágicas são encontradas à necropsia dos animais acometidos, como petéquias no córtex renal, no epicárdio, esplenomegalia (OLIVEIRA, 2009), pulmões congestos e edematosos (CAMEROM, 2011).

$\mathrm{Na}$ forma crônica ocorre artrite com engrossamento das articulações e acúmulo de conteúdo sanguinolento na cápsula articular (lesão que pode evoluir para fibrose), em casos mais raros pode ocorrer insuficiência cardíaca causada por endocardite vegetativa devido à proliferação de tecido granular nas válvulas do coração (SOBESTIANSKY et al., 1999c). O diagnóstico terapêutico é facilmente aplicado no caso da erisipela utilizando penicilinas, que levam a melhora significativa dos animais na fase aguda ainda nas primeiras 24 horas, facilitando a diferenciação de outras enfermidades (CAMEROM, 2011). 
Os testes laboratoriais para o diagnóstico também podem ser utilizados. O cultivo e isolamento da bactéria podem ser realizados a partir de materiais de animais infectados (sangue, pele, fezes, tonsilas e baço), além de outros métodos mais modernos como ELISA e fixação do complemento (OLIVEIRA, 2009; SOBESTIANSKY et al., 1999c).

Ainda segundo Oliveira (2009) a infecção por E. rhusiopathiae em suínos, deve ser diferenciada de outras infecções, principalmente as causadas pelo vírus da peste suína clássica e por Salmonella choleraesuis, pois ambas enfermidades apresentam sinais septicêmicos semelhantes.

\section{Salmonelose suína}

A salmonelose é uma enfermidade causada por bactérias do gênero Salmonella spp que pode assumir as formas septicêmica e entérica. Os principais agentes causadores de doenças nos suínos, são as espécies $S$. choleraesuis e $S$. enteritidis sorovar typhimurium. (SOBESTIANSKY et al., 1999d). A mortalidade nos casos septicêmicos pode chegar a 100\%, com mortes ocorrendo em 24-48 horas (GYLES, 2010). Surtos de salmonelose septicêmica são raros e frequentemente estão relacionados à introdução de animais previamente infectados em rebanhos, sendo a rota oral é a via de infecção mais comum (GYLES, 2010).

A enfermidade pode se apresentar também nas formas aguda e crônica. Na primeira observa-se aumento da temperatura corporal, queda no apetite, enfraquecimento, tendência a se amontoar, diarreia (menos frequente) e áreas avermelhadas na pele, geralmente nas orelhas, barriga e região inguinal (SOBESTIANSKY et al.,1999d). $\mathrm{Na}$ forma crônica os animais apresentam febre, queda de apetite e diarreia, essa última podendo durar semanas com fezes liquidas mal cheirosas, de coloração amareladas ou até mesmo sanguinolentas, com material necrótico (SOBESTIANSKY et al.,1999d).

As lesões encontradas em necrópsias incluem focos hemorrágicos na mucosa estomacal com áreas de perda de mucosa, petéquias nos rins, bexiga, epiglote e epicárdio, o baço se encontra aumentado e no pulmão são notadas áreas hemorrágicas e focos pneumônicos purulentos. Na forma crônica notam-se áreas necrosadas na mucosa do ceco e cólon, com espessura aumentada, coloração amarelada ou escurecida e linfonodos mesentéricos aumentados (SOBESTIANSKY et al., 1999d).

Segundo Gyles (2010), o diagnóstico depende da avaliação dos sinais clínicos junto com exames laboratoriais de fezes e tecidos dos animais afetados, ainda a avaliação da qualidade da água e do alimento fornecido é importante para que esses não ajudem a disseminar a enfermidade. É necessário diferenciar o quadro clínico da salmonelose do quadro de outras doenças, como erisipela, PSC, PSA e pasteurelose. Devido à associação dessa doença com a PSC, 
recomenda-se que em casos clínicos de salmonelose sempre se faça exame virológico para PSC, para se eliminar a possibilidade de uma infecção conjunta (SOBESTIANSKY, 1999d).

\section{Pasteurelose}

A pasteurelose é uma doença oportunista, que geralmente surge como complicação da pneumonia por Mycoplasma hyopneumoniae. Na maioria dos casos a Pasteurella multocida tipo A é o agente causador, a enfermidade é caracterizada principalmente por um quadro de broncopneumonia exsudativa, podendo ser acompanhada de pericardite, pleurite e septicemia em leitões e porcos adultos (CEBRA, 2008).

A forma septicêmica pode afetar animais de diferentes idades conforme o sorotipo da bactéria, o sorotipo B, encontrado na Índia, infecta animais de todas as idades e o sorotipo D, evidenciado na Austrália, acomete animais entre 14 e 22 semanas, já os leitões neonatos são os mais susceptíveis podendo ir a óbito dentro de 12 horas (RADOSTITS et al., 2002). As lesões encontradas ao exame dos suínos mortos são edema na região da faringe, manchas azuladas no abdômen e orelhas, focos hemorrágicos, congestão de superfícies serosas e lesões vasculares, que ao exame histopatológico observam-se trombos e bactérias dentro dos vasos (RADOSTITS et al., 2002).

A doença possui três formas: aguda, subaguda e crônica. Na forma aguda, animais mostram dispnéia, prostração, febre alta $\left(42^{\circ} \mathrm{C}\right)$ e animais mortos ou moribundos podem apresentar descoloração púrpura da região abdominal, enquanto que na subaguda, os animais apresentam somente tosse e respiração abdominal na fase de crescimento/terminação (PIJOAN, 1992). Já a forma crônica, mais comum, afeta os leitões no final da etapa de creche e início de crescimento, nesse caso observa-se tosse esporádica, febre baixa ou inexistente e contrações espásticas do abdômen (PIJOAN, 1992). A Pasteurella multocida também é listada como um dos agentes causais da Síndrome Dermatite Nefropatia Suína (THOMSON et al., 2002),

Para se chegar ao diagnóstico, é indicada a associação do histórico clínico com o isolamento do agente, que pode ser realizada a partir de suabe traqueobronquial com posterior semadura em ágar sangue (PIJOAN, 1996). Para a forma septicêmica RADOSTITS et al. (2002) indica o isolamento do agente a partir de amostras de rins, baço e fígado, além do pulmão e linfonodo bronquial. Além da utilização de meios de cultura específicos para o isolamento e identificação da P. multocida, Borowski (2006) cita a inoculação de material suspeito em camundongos e técnicas moleculares como outras formas de se chegar a um diagnóstico final. 


\section{Formas de diferenciação}

Pode-se perceber que as doenças as quais esta revisão trata, apresentam sinais clínicos muito semelhantes, dificultando algumas vezes o diagnóstico e a diferenciação entre elas. A Tabela 1 abaixo foi elaborada justamente com o intuito de organizar a diferenciação entre as enfermidades.

Tabela 1. Lesões diferenciais entre as principais enfermidades hemorrágicas dos suínos

\begin{tabular}{|c|c|c|c|c|c|}
\hline \multirow[t]{2}{*}{ Lesões } & \multicolumn{4}{|c|}{ Enfermidades } & \multirow[b]{2}{*}{ Erisipela } \\
\hline & PSC & PSA & Pasteurelose & Salmonelose & \\
\hline $\begin{array}{l}\text { Petéquias na } \\
\text { serosa de } \\
\text { órgãos }\end{array}$ & Sim & Sim & Sim & Sim & $\mathrm{Sim}$ \\
\hline $\begin{array}{l}\text { Cianose das } \\
\text { Extremidades/ }\end{array}$ & Sim & Sim & Sim & Não & Sim \\
\hline $\begin{array}{l}\text { Abdome } \\
\text { Eritema da pele }\end{array}$ & Sim & Sim & Sim & Sim & Sim \\
\hline $\begin{array}{l}\text { Pulmões } \\
\text { congestos e } \\
\text { edematosos }\end{array}$ & Não & Sim & Sim & Não & Sim \\
\hline Esplenomegalia & Sim & Sim & Não & Sim & Sim \\
\hline Artrite & Não & Não & Sim & Sim & Sim \\
\hline $\begin{array}{l}\text { Fezes } \\
\text { sanguinolentas }\end{array}$ & Não & Sim & Não & Sim & Não \\
\hline Diferencial & $\begin{array}{c}\text { Infartos } \\
\text { multifocais na } \\
\text { borda do baço }\end{array}$ & $\begin{array}{c}\text { Lesões } \\
\text { hemorrágicas } \\
\text { de grande } \\
\text { intensidade }\end{array}$ & $\begin{array}{c}\text { Enfermidade } \\
\text { oportunista / } \\
\text { respiração abdominal }\end{array}$ & $\begin{array}{c}\text { Diarréia de } \\
\text { longa duração } \\
\text { aquosa e fétida }\end{array}$ & $\begin{array}{c}\text { Lesões } \\
\text { losangulares } \\
\text { na pele, } \\
\text { Endocardite } \\
\text { Vegetativa }\end{array}$ \\
\hline
\end{tabular}

A Erisipela é a doença mais simples de se identificar, uma vez que as lesões hemorrágicas em forma de losango espalhadas pelo corpo do animal são consideradas sinal patognomônico dessa enfermidade (OLIVEIRA 2009). Além, na forma crônica ocorre engrossamento das articulações devido ao processo de artrite ocasionado pela infecção e lesões características nas válvulas cardíacas (SOBESTIANSKY et al.,1999c). O diagnóstico terapêutico também é de grande valia, uma vez que o tratamento com penicilinas é efetivo e resulta em melhora rápida dos sinais clínicos, o que não se observa nas outras enfermidades (CAMEROM, 2011).

No caso da PSC e PSA, ambas as doenças apresentam sinais clínicos e epidemiologia muito semelhantes entre elas, o que dificulta a diferenciação, apesar da literatura em alguns casos afirmar que a PSA se apresenta com lesões mais hemorrágicas, maior mortalidade e morbidade quando comparada a PSC. Por isso, o uso de técnicas de isolamento virológico para a diferenciação é a única alternativa viável, uma vez que os agentes etiológicos são vírus antigenicamente diferentes. 
Lesões eritematosas em regiões de focinho, orelhas e barriga podem ser confundidas com infecções por Pasteurela ou Salmonella. Nesse caso, trabalhar com exames de isolamento bacteriano é a melhor alternativa. Na salmonelose a infecção pode estar associada com a infecção pelo o vírus da PSC, sendo assim, um isolamento positivo de Salmonella deve ser acompanhado de exame virológico de PSC negativo.

O fato de a pasteurelose ser uma doença de caráter oportunista ao contrário das outras citadas possibilita e facilita o diagnóstico e a diferenciação, pois se os animais que apresentam manchas hemorrágicas em focinho, orelhas e abdome já estiverem sendo afetados por outras doenças, principalmente do trato respiratório deve-se desconfiar de haver infecção conjunta com Pasteurella. Outro sinal importante é a respiração abdominal e espástica dos animais afetados, uma vez que o agente etiológico afeta principalmente o sistema respiratório, ao contrário das outras enfermidades aqui relatadas. $\mathrm{O}$ isolamento bacteriano a partir de suabe traqueobrônquico ou de órgãos é útil para a confirmação.

\section{CONSIDERAÇÕES FINAIS}

A atualização sobre as enfermidades que cursam com quadros hemorrágicos é fundamental para o médico veterinário e constitui-se na a melhor forma de investigar e ter melhor acurácia nos diagnósticos. A importância deste trabalho merece grande destaque para o sistema nacional de defesa sanitária animal que objetiva o controle e erradicação da Peste Suína Clássica no Brasil. As características das enfermidades relatadas reforçam e fundamentam um sistema de vigilância sanitária e justificam o constante trabalho no diagnóstico diferencial. Ademais, para a cadeia produtiva de suínos a presença desses patógenos no sistema de criação podem gerar grandes prejuízos e até inviabilizar a produção.

\section{REFERÊNCIAS}

BERSANO, J.G; VILLALOBOS, E.M.C; BATLOUNI, S. R. Pesquisa do vírus da Peste Suína Clássica em suínos sadios abatido em matadouros do estado de São Paulo Arquivos do Instituto Biológico, São Paulo, v.68, n.1, p.09-12, 2001.

BLOOD, D. C.; RADOSTITS, O. M. Peste suína Africana (doença dos porcos africanos, doença dos javalis). In: BLOOD, D. C.; RADOSTITS, O. M. Clínica Veterinária, 7th.ed. Rio de Janeiro, Guanabara Koogan, 1989, Chap. 21. p. 671- 674. b. 
BLOOD, D. C.; RADOSTITS, O. M. Peste suína Clássica (Febre suína). In: BLOOD, D. C.; RADOSTITS, O. M. Clínica Veterinária, 7.ed. Rio de Janeiro, Guanabara Koogan, 1989. Chap. 21. p. 665-671. a.

BOROWSKI, S.M. Pasteurelose pulmonar: uma atualização. Porto Alegre: Centro de Pesquisa Veterinária "Desidério Finamor", Laboratório de Patologia Suína, 2006. 6p. Disponível em: http://www.cnpsa.embrapa.br/abravessc/pdf/Palestras2001/Sandra_Borwski.pdf >. Acesso em: 27 jan. 2013.

CAMEROM, R.D.A.; Swine Erysipelas. In: KAHN, C.M. (Ed.). The Merck Veterinary Manual. 9.ed. Whitehouse Station: Merck Sharp \& Dohme Corp, 2011.

CEBRA, M.L. Pasteurellosis. In: KAHN, C.M. (Ed.). The Merck Veterinary Manual. 9. ed. Whitehouse Station: Merck Sharp \& Dohme Corp., 2008.

EDWARDS, S. Classical Swine Fever. In: KAHN, C.M. (Ed.). The Merck Veterinary Manual. 9th.ed. Whitehouse Station: Merck Sharp \& Dohme Corp., 2010.

GYLES, C.L. Salmonellosis: Introduction. In: KAHN, C.M. (Ed.). The Merck Veterinary Manual. 9.ed. Whitehouse Station: Merck Sharp \& Dohme Corp., 2010.

IMADA Y.et al. Enzyme-linked immunossorbent assay employing a recombinant antigen for detection of protective antibody against swine erysipela. Journal of Clinical Microbiology. v.41. p.5015-5021, 2003.

KRZYZANIAK, E. L.et al. Difusão da Peste Suína Clássica no estado de São Paulo por mobilização de suínos. Unimar Ciências. v. 11, n.1/2, p 51-58, 2002.

MAYR, A., GUERREIRO, M. G. Vírus da Peste Suína. In: MAYR, A.; GUERREIRO, M. G., Virologia Veterinária. Porto Alegre: Sulina, 1972. p. 319-331.

MOURA, J.A. Peste Suína Africana no Brasil: a epidemiologia, os registros históricos, a erradicação da doença e o desenvolvimento da suinocultura nacional pós-ocorrência 2009. 135f. Dissertação (Mestrado em Ciências Animais) - Universidade Nacional de Brasília, 2009.

OIE; Organização Mundial da Saúde Animal. Classical Swine Fever (hog cholera). OIE Scientific and Technical Department. 5p. Paris. 2009. Disponível em: http://www.oie.int/fileadmin/Home/eng/Animal_Health_in_the_World/docs/pdf/CLASSICAL_S WINE_FEVER_FINAL.pdf Acesso em: 24 jan. 2013

OLIVEIRA, S.J. Erisipela suína: sempre importante à suinocultura. Acta Scientiae Veterinariae, Porto Alegre, v.37, n.1, p.97-104, 2009. Disponível em: http://www.suinotec.com.br/arquivos_edicao/IV_SINSUI2009_11_SJ_de\%20Oliveira.pdf . Acesso em: 26 jan. 2013.

OLSEN, C.W. Erysipelas. Madison: Department of Pathobiological Sciences, School of Veterinary Medicine, University of Wisconsin-Madison, 2004. Disponível em: http://www.vetmed.wisc.edu/pbs/zoonoses/Erysipelas/erysipelasindex.html Acesso em: 26 jan. 2013.

OIRSCHOT, J. T. V. Classical Swine Fever (Hog cholera) . In: LEMAN, A. D.et al. (Ed.) Diseases of Swine. 8.ed. Ames. Iowa State University Press, 1999. p. 159-171. 
PIEROZAN, R.L.et al.Síndrome hemorrágica intestinal e outras patologias hemorrágicas do sistema digestivo dos suínos. Suinocultura em foco, Porto Alegre, ed. 8, p. 3-5, 2008.

Disponível em: http://www.suinoculturaemfoco.com.br/fd/sanidade8.html Acesso em: 26 jan. 2013.

PIJOAN, C. Pneumonic Pasteurellosis. In: LEMAN, A.D.et al.(Ed.). Diseases of Swine. 7.ed. Ames: Iowa State University Press, 1996. Chap.44, p.552-559.

RADOSTITS, O.M. Pasteurelose Septicêmica. In: RADOSTITS, O.M.et al. Clínica Veterinária. Rio de Janeiro: Guanabara Koogan, 2002. p.768.

SANCHEZ-VIZCAINO, J. M. African Swine Fever. In: LEMAN, A. D.et al. (Ed.) Diseases of Swine. 7. ed. Ames. Iowa State University Press, 1992. p. 228-241.

SOBESTIANSKY, J.; Erisipela. In: SOBESTIANSKY, J. et al. Clínica e patologia suína. Goiânia: Art3, 1999. p.149-151.c

SOBESTIANSKY, J.; Peste Suína Africana. In: SOBESTIANSKY, J.et al. Clínica e patologia suína. Goiânia: Gráfica Art3, 1999. p. 334-341. b

SOBESTIANSKY, J. Peste suína clássica. In: SOBESTIANSKY, J.et al. Clínica e patologia suína. Goiânia: Art3, 1999. p.341-349 a

SOBESTIANSKY, J. Salmonelose. In: SOBESTIANSKY, J.et al. Clínica e patologia suína. Goiânia: Art3, 1999. p.383-387.d

THOMSON, J.R.et al. Porcine dermatitis and nephropathy syndrome. clinical and pathological features of cases in the United Kingdom (1993-1998), v.49, n.8, p.430-437, 2002. Journal of Veterinary Medicine. A, Physiology, Pathology, Clinical Medicine.

TOKARNIA, C. H.et al. O surto de Peste Suína Africana ocorrido em 1978 no município de Paracambi, Rio de Janeiro. Pesquisa Veterinária Brasileira. v. 24, n.4, p. 223-238, 2004. 